\title{
Exploring the barriers to upscaling the production capacity of the edible insect sector in the United Kingdom
}

\begin{abstract}
Purpose: This study aims to explore the barriers to upscaling the production capacity of the edible insect sector in the UK and to identify the impact of current regulation on the sector's development.
\end{abstract}

Design/methodology/approach: A significant proportion of edible insect companies within the UK were identified through an online market research database and contacted via email to invite them to participate in this study. Phone interviews were conducted with ten companies. Thematic analysis was adopted for data analysis.

Findings: There were five themes identified as barriers to upscaling the production capacity for the edible insect sector in the UK: feeding materials, production capacity, expertise and knowledge, new product development and regulatory uncertainty.

Research limitations/implications: This research was based on a qualitative study. Further quantitative research is needed to test the extent of the impact of these five themes on upscaling production capacity. In addition to production capacity, marketing and consumers' acceptance, culture and behavior can also be considered in future studies.

Originality: This study makes a significant contribution to the literature by providing insight on the barriers to upscaling production capacity in the edible insect sector.

Keywords: edible insect sector, production capacity, upscaling challenges, regulatory framework 


\section{Introduction}

The production and habitual consumption of animal meat has encountered criticism in recent years due to environmental concerns about land and water usages, pollution and gas emissions (Steinfeld et al., 2006). The process of raising livestock animals alone contributes to approximately half of all food-generated greenhouse gas emissions (GGE) (Celia et al., 2016). It is believed that cutting out meat consumption altogether in the UK would save an estimated 22\% of GGE from the UK food chain (Berners-Lee et al., 2012). In addition, there is medical evidence that heavy, habitual consumption of meat products increases the risk of developing several medical conditions (Wolk, 2017). In recent years, a growing awareness in the population about healthy and sustainable food has led to a rising interest in meat analogues. A rapidly growing number of consumers are reducing their daily meat consumption and demanding healthy and tasty meat analogues. Various meat analogues have been developed to replace meat products. Meat analogues provide better sustainability, technological feasibility, economic viability and similarity with societal dietary patterns (van der Weele et al., 2019).

While different meat analogues have been produced, e.g. algae and cultured meat, insect meat has been recognised as a dietary cornerstone across the world. It is estimated that insect meat is eaten habitually by at least 2 billion people worldwide (Taylor and Wang, 2018). In fact, people have been eating insect meat for a long time, and it represents a component of the traditional diets of over 113 countries (MacEvilly, 2000). A considerable number of insect species have become meat replacements because of their favourable nutritional profile, with low fat and a high protein content (Kouřimská and Adámková, 2016). Insect meat does not only provide advantages over traditional livestock animals but 
has also been labelled as a sustainable source of protein. However, the current insect rearing process highly depends on manual labour. The volume of edible insect production is also small, although insect species offer varying opportunities and suitability for human consumption (Rumpold and Schlüter, 2013). To moderate production and labour costs, it is essential to implement technology and to upscale production capacity (Rumpold and Schlüter, 2013). In addition, the impact of current regulatory frameworks on the production and sale of edible insect products represents a challenge to the sector. Most studies on edible insect food products have focused on the aspects of nutrition, science and cultural/consumer acceptance. there is a lack of study on production barriers from an operations perspective. In addition, there have been no studies on the UK insect food sector yet, although the academic literature has examined the challenges to the sector within Europe (Payne et al., 2016 and Brunner and Nuttavuthisit, 2019) and in other nations e.g. Thailand and South Korea (Han et al., 2017). Therefore this study aims to explore the barriers to upscaling the production capability of the edible insect sector in the UK and to identify the impact of current regulatory frameworks and future regulation uncertainty on the sector's development.

The structure of the paper is as follows: the next section will provide background information on the barriers to upscaling the production capacity of the edible insect sector, which is followed by the research methods, including data collection and data analysis. Finally, the discussion and the implications of these results are presented to provide academic and practical advice. The conclusion is then drawn, with research limitations and future research directions.

\section{Literature Review}


Edible insect products are generating increasing global awareness as a rapidly growing number of consumers demand healthy and tasty meat analogues. Edible insect products provide significantly higher animal protein than most other meat from animal species conventionally used in modern agriculture (Halloran et al., 2016). For example, cricket raising results in 100 times less GGE than beef production, and crickets also have higher proportions of protein than beef or chicken. There is a new trend focusing on using insects to provide food with high protein via established delivery systems, e.g. energy bars and protein powder. American and European manufacturers also make flour from insects, and then use the flour for snacks and even insect-enriched pasta, which can be produced on a large scale in order to make insect products more acceptable to customers and to reduce consumer rejection (Caparros Megido et al., 2016). In addition, insect species have an exceptionally high micronutrient profile (Payne et al., 2015). Edible insect products can provide supplements to the people in micronutrient-deficient risk groups, e.g. the elderly community, who are at a heightened risk of several deficiencies such as Vitamin D, Vitamin K, magnesium and selenium (Hoffman, 2017). However, the edible insect sector faces significant challenges. Among them is the acceptance of insects as a food source (Verbeke, 2015). Consumer acceptance has been observed to vary considerably depending on an individual's cultural background (Hartmann et al., 2015). Consumers also have concerns about insect food safety and quality due to a lack of legislation that effectively regulates insect rearing and marketing processes (Lähteenmäki-Uutela et al., 2018).

\section{Current status of the edible insect sector in the UK}

In recent years, while edible insect production in other European countries has been growing, UK companies are considered to be at a very early stage of its development (Winther, 2018). Most insects are sourced through foraging of their natural environments (Codex 
Alimentarius Commission, 2010). However, the continued collection of insects from their natural habitats has been deemed unsustainable, as it results in the overexploitation of insect reserves (Schabel, 2010). Also, there is a lack of regulation on the production process, product quality and food safety. However, some regions across the world have established insect farming sectors, e.g. the Asian Pacific region. The mass production of certain insects (e.g. sericulture for silk and apiculture for honey) for human food has an extended history (Dobermann et al., 2017). A selection of the model characteristics of an ideal insect species, intended for mass production and human consumption, includes high productivity, disease resistance, high egg production and capacity to survive in high density populations (Rumpold and Schlüter, 2013).

In addition, current edible insect producers heavily depend on manual labour for extensive production processes such as rearing, harvesting and post-harvest processing (Rumpold and Schlüter, 2013). The lack of automated processing technology results in significant manual labour costs and high product prices, e.g. in Europe the price of insect products per unit is the same as that of animal meat (Rumpold and Schlüter, 2013). Insect producers also have few choices for their insects' food source. Within the EU, the opportunity to use food waste products as feeding material for edible insects is limited. The raising of insects intended for both animal consumption and human food is prohibited, and, as insects are officially recognised as livestock, so is using K3 materials, which is organic waste sourced from animal carcasses, kitchen and food waste to feed insects (Stamer, 2015). An inability to use an extensive range of waste products for insect feed may impact negatively on the cost and sustainability of insect production. Furthermore, the nutritional profile of insects has been observed to vary considerably with feed composition (Rumpold and Schlüter, 2013). 
To achieve competitive prices, as well as to protect wild insect populations (although mass rearing/farming in edible insect sectors with a sustainable environmental impact is theoretically possible) business organisations still face major barriers to upscaling their production capacity (van der Weele et al., 2019; Tuomisto and Teixeira de Mattos, 2011). Therefore, it is essential to understand their current challenges and find the optimum equilibrium to minimise cost and maximise the efficiency of 'mechanisation, automation, labour, investment, and productivity’ (Cortes Ortiz et al., 2016).

\section{Impacts of the current regulatory framework}

The present legal framework was cited as one of the primary factors impeding the growth of the edible insect sector in a 2018 industry questionnaire survey (IPIFF, 2018a). The changes in the EU regulatory framework at the beginning of 2018 changed edible insects into a fully regulated component of the food sector (Food Ingredients First (FIF), 2018). The European Food Safety Authority (EFSA) needed the organisations to submit an application for approval by the beginning of 2018 for a 2-year transition period (Dobermann et al., 2017). This change meant that edible insects were regulated, while they had previously been considered a legislative 'grey area' (Food Ingredients First, 2018). However, these changes also caused a significant degree of uncertainty, especially for British companies after Britain's exit from the European Union. It is currently unclear if the UK's Food Standards Agency will continue to adhere to the regulations set by the EFSA. This could result in an increase in legislative freedom, providing a boost to the industry (Dobermann et al., 2017), although it could also result in the UK edible insect sector failing to benefit from any further changes to food regulation within the EU. Lähteenmäki-Uutela et al (2018) stated that there is no specific EU-level regulation on the 
breeding and marketing of insects intended for human consumption. Although there are opportunities for the creation of new edible insect products, current regulatory frameworks restrict industry development and cause uncertainty. An unstable policy environment caused by present legislative ambiguity and future uncertainty could result in a deficiency of industry investment (Hoffmann et al., 2009). In fact, regulatory uncertainty promotes a wait-and-see phenomenon for potential investors and contributes to stagnation in the development of the emerging edible insect market. As most edible insect producers are small and medium sized enterprises (SMEs), they need financial input from investors to facilitate technological breakthroughs and upscale productions (van der Weele et al., 2019). However, although there is huge attention from investors on the food industry, investors focus more on technological challenges and large companies that fit economic models of innovation, and do not focus on operations and production in SMEs.

\section{Research Methods}

\section{Systematic literature review}

This study aims to explore the barriers to upscaling the production and processing of the edible insect sector in the UK and to identify the impact of current regulatory frameworks and future regulatory uncertainty in the sector's development. Due to the niche research focus in this study, a wide range of sources and information were searched in leading databases to minimise bias, such as EBSCO, Emerald, Science Direct, Taylor and Francis and Web of Science. In order to narrow down on the focuses of this study, key words related to insect, production and regulatory influences were developed as search criteria and used with different combinations (Table 1). 
Table 1. Data search strings

\begin{tabular}{|c|c|c|}
\hline & Focuses & Construction \\
\hline String 1 & $\begin{array}{l}\text { Novel } \\
\text { insect }\end{array}$ & $\begin{array}{l}\text { "history of insect consumption” OR “format of insect food delivered” } \\
\text { OR “edible insect species” OR “edible insect farming” OR “edible } \\
\text { insect rearing” OR “edible insect production” OR “edible insect feed” } \\
\text { OR “insect recipes” OR “insect benefits” OR “insect nutritional } \\
\text { profile” OR “novel insect” }\end{array}$ \\
\hline String & $\begin{array}{l}\text { Sustainab } \\
\text { le } \\
\text { productio } \\
\text { n }\end{array}$ & $\begin{array}{l}\text { “GHG emissions” OR “land usage” OR “energy employed” OR “green } \\
\text { energy” OR “livestock pollution” OR “pollutant emissions” OR “UK } \\
\text { emissions” OR “UK food chain emissions” OR “wasted food” OR } \\
\text { “food security” OR “waster utilised” OR (“sustainability” AND “insect } \\
\text { production”) OR (“sustainable” AND “insect production”) }\end{array}$ \\
\hline String & $\begin{array}{l}\text { Regulator } \\
\text { y } \\
\text { influence } \\
\text { s }\end{array}$ & $\begin{array}{l}\text { “regulatory influences” OR “approval routes” OR “effect on insect } \\
\text { industry” OR “alterations” OR “authorised list” OR “edible insects” } \\
\text { OR “regulation on feed” }\end{array}$ \\
\hline
\end{tabular}

After deleting duplicated records across different databases, there were 483 papers left from various disciplines such as nutritional value, ecology, food safety, legislation, regional development, waste management and consumer preference. All these articles were read thoroughly and individually evaluated. This has led to the final inclusion of 58 articles on production and regulation changes in the edible insect sector, and those articles have been published in a large number of academic journals (Figure 1). The references used in these publications were cross-checked to make sure we did not miss any potential contributions. 


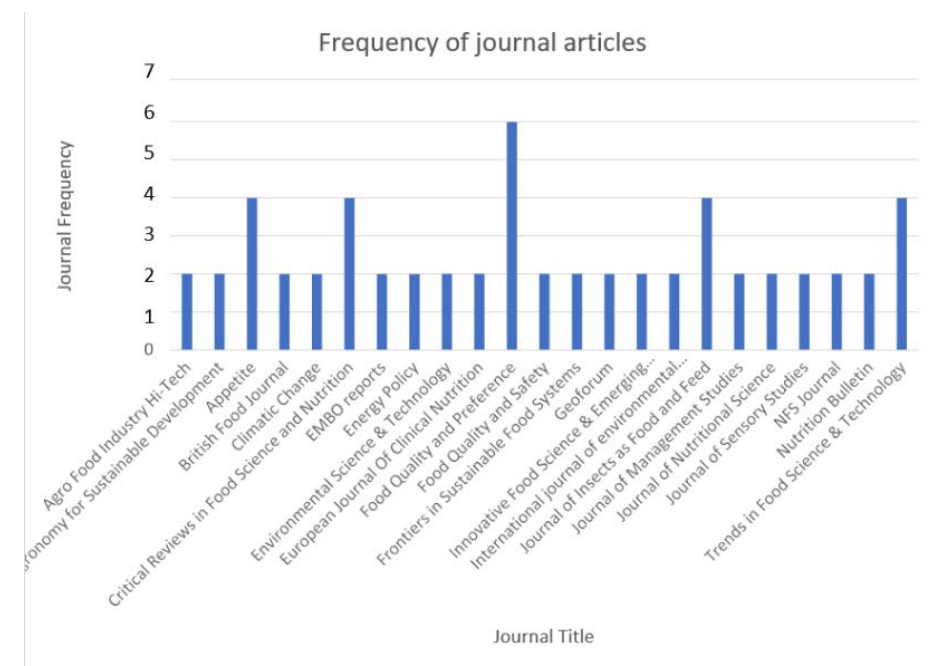

Figure 1. Journal publication on edible insect products

\section{Interview}

Research into the edible insect sector within the UK is still in a very early stage, therefore qualitative methods have been adopted in order to construct an understanding of the selected participants' experiences (Pathak et al., 2013). Semi-structured interviews were conducted to provide a useful way for researchers to learn about this new field (Qu Sandy, 2011). Interview questions (Appendix A) were identified through the literature review. Several connected questions stemmed from the mentioned barriers, which were further refined. Open questions were employed in order to allow for a greater degree of flexibility and optimally facilitate an extensive and developmental answer (Saunders et al., 2008 and Yin, 2017). The interview questions were pilot tested by academic staff and practitioners.

\section{Participant selection and sampling methods}

A significant proportion of insect producers in the UK were identified through the online market research database and contacted via email to invite them to participate in this study. The criteria for selection were based upon purposive sampling. This sampling methodology 
selects units for research on the basis of pre-specified attributes, experiences and qualities that facilitate an in-depth examination of the research aims (Maruster and Gijsenberg, 2013). Selected participants were identified, with a minimum of 3 years' experience within the operations, supply chain, management or consultancy within the UK edible insect sector. Ten companies agreed to join the study (Table 2). All interviews were conducted in 2019 and audio recorded, with consent from the participants to develop interview transcripts. Interviews were conducted until the researchers deemed that saturation had occurred, which is when, according to Given (2015), further data collected through interviews no longer creates emergent themes. Although case numbers were limited, in researching a novel area/field, even a single sample has been identified as 'highly informative and meaningful' (Boddy, 2016).

Table 2. Participant Profile

\begin{tabular}{|l|c|c|c|}
\hline $\begin{array}{l}\text { Case } \\
\text { company }\end{array}$ & $\begin{array}{c}\text { Position in the supply } \\
\text { chain }\end{array}$ & $\begin{array}{c}\text { Employee } \\
\text { numbers }\end{array}$ & $\begin{array}{c}\text { Role of the } \\
\text { interviewee }\end{array}$ \\
\hline 1 & Food Brand & $10-50$ & Operations Manager \\
\hline 2 & Food Brand & $10-50$ & Operations Manager \\
\hline 3 & Farming/ Production & $<10$ & Owner/manager \\
\hline 4 & Pressing & $<10$ & Researcher/Network Director \\
\hline 5 & Food Brand & $10-50$ & Manager \\
\hline 6 & Farming/ Production & $<10$ & Owner/manager \\
\hline 7 & Pressing & $<10$ & General manager \\
\hline 8 & Food Brand & $<10$ & Consultant \\
\hline 9 & Farming/ Production & $<10$ & Owner \\
\hline 10 & Farming/ Production & $<10$ & Manager \\
\hline
\end{tabular}

\section{Data analysis}

Thematic analysis, a strategy involving identifying, analysing and reporting patterns within data, was adopted to analyse the data (Weber, 1990, Neuendorf, 2002, Braun and Clarke, 2006). After the interview transcripts were generated, stimulating processes were involved to develop codes in order to improve understanding of the collected data. Initially, the researchers manually broke the narrative into sentences and paragraphs related to particular focuses (Weber, 1990) for the first two company interviews. This process gave the researchers greater 
insight into the specific focuses of each interview. Coding was defined and gradually converted into usable data through the identification of concepts, or ideas that had some connection with each other. Through the development of codes, the data was highlighted and categorised into clusters. The researchers moved back and forth from interview transcripts to search for various aspects of production and regulatory challenges in the interviews. The codes were further reviewed and developed by theme. Potential overarching themes were formed from the identification of links between codes within the data (Braun and Clarke, 2006). Tables were utilised to group codes together into emergent themes facilitating their development. The two researchers discussed the similarities and differences identified in the coding process, and the matrix was adjusted to ensure greater consistency in the remaining interviews. After the review of themes, each theme was individually examined to distinguish their core qualities and how each theme framed them. Defined themes (in Figure 2) were also inspected against the wider context of the research to prevent redundant theme overlap.

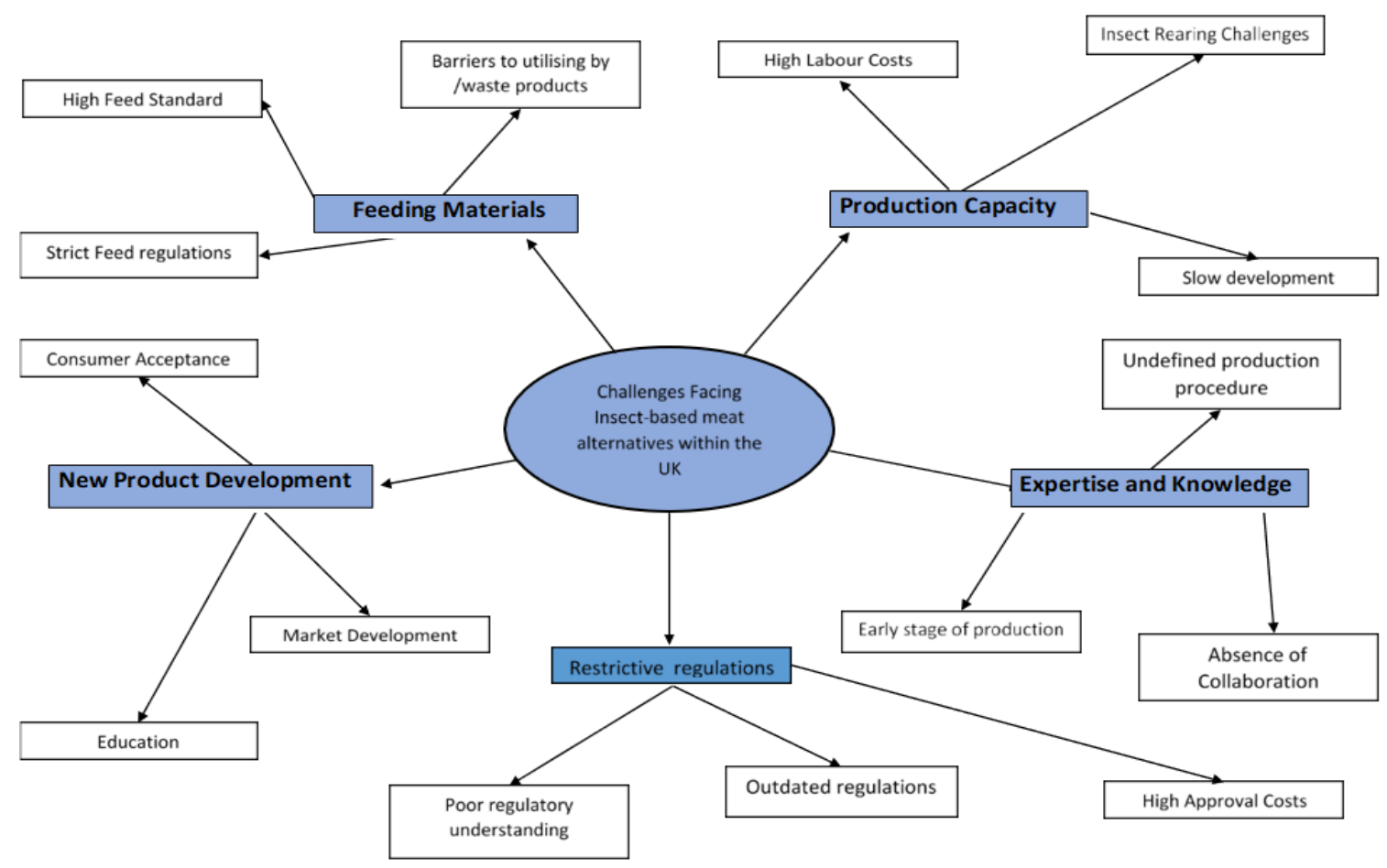

Figure 2: Diagram of themes developed from thematic analysis 


\section{Research findings}

Five themes were distinguished corresponding to the upscaling challenges faced by the edible insect sector in the UK: insect feeding materials, production capacity, expertise and knowledge, new product development and regulatory uncertainty.

\section{Insect feeding Materials}

The interviewees emphasised that high-standard insect feeding materials were required for "all” livestock bred to be "human-grade food within the EU” (Participant 2). In the past, certain forms of livestock feed, such as chicken feed, were employed as insect feeding material to avoid potential costs. In fact, a range of different feeds were utilised by insect farms and producers before the EU regulations officially changed edible insects into a fully regulated food source. Following this regulation, feeding material for insect farming had to meet a predetermined quality standard. "Because [the regulatory body] needs verification [that] the processing or making meets regulations" (Participant 1). Food brands have even established policies on insect feeding material. Insect farmers must provide detailed records on insect feeding material to get their insects to be considered by food makers. "Food brands do use certified feeding materials: they are all very strict. We can only buy from certified suppliers, who can provide specification on feeding material intake” (Participant 1). Traditional livestock feed, used to reduce insect farming costs, must be switched to certified plant-based or waste products. Using waste products for insect feeding material could present promising opportunities. However, there are significant barriers to using some forms of waste as animal feed. Consumers would like to know how insects are fed. "We know insects feed off waste and that would be ideal, but obviously we can't put them in the food chain and it would be much tougher to sell" (Participant 6). The 
strategy of using waste plant material for small-scale insect farms was identified by an interviewee. "Some smaller farms have been using waste products from local restaurants and greengrocers, e.g. waste vegetable products" (Participant 4). Therefore, it is necessary to develop a strategy to work with local businesses to use waste to provide affordable feeding materials for these farms.

\section{Production processes}

The production processes of the edible insect sector are considered underdeveloped compared to traditional agriculture sectors. Insect production has a low level of productivity in labour and land utilisation, because they use a high degree of manual labour due to lack of automation and material handling equipment. The operations of UK insect farms were considered by the interviewees to be lagging in terms of production technology. "I'd say most, if not all, insect farms in the world are lacking in technology" (Participant 1). "There is an unreasonable length of time and dependence on labour in the production process” (Participant 8). “We are still literally growing insects in a box, sort of batch production" (Participant 5). As most businesses in the edible insect sector are SMEs, labour costs are a major challenge to the upscaling of production. They struggle to pay labour costs and to operate sustainably. It was stated that "getting from start-up to big business is quite a big deal in regard to the labour costs" (Participant 4). One interviewee also stated that “a couple of companies have pulled out because they didn't think it was feasible in regard to the time and labour involved" (Participant 7). Organisations in the Netherlands were referenced for the degree of technology implemented in their productions. "Their businesses could probably have 4 to 5 times our production volumes in a square foot; non-UK companies are further ahead in things like automation” (Participant 9). The interviewees also stated that "The edible insect sector is not only 
labour intensive in the UK, but it is also energy intensive” (Participant 3).

\section{Expertise/ knowledge}

People operating in the edible insect sector are from a wide variety of fields, from academic researchers to insect farmers. "They don't have historical, specialist knowledge from the food sector" (Participant 1). Although many people in the sector have a comprehensive understanding of entomology (the scientific study of insects), there is currently a perceived deficiency of knowledge about the optimal conditions and practices for insect farming. The intricacies of insect farming also have no established procedure. There is a significant amount of variation in the "optimal methods" in the insect farming process. "There are $a$ lot of unforeseen problems that you have to overcome, because we are still setting up our processes” (Participant 9). In addition, most of edible insect producers lack knowledge about business and management, and commercial experience about food products. These individuals may not prioritise the basics of food production e.g. scaling and reducing pricing.

\section{New Product Development}

Currently, as the edible insect sector benefits from several general consumer trends, sector development strategies need to maintain public interest in the sector and to prevent its regression. In addition, edible insect products face challenges in new product development. Firstly, the format in which the product is delivered to consumers is considered critical for consumer acceptance. Insect products need to be produced in formats which consumers are familiar with in order to increase the uptake of product offerings. "Could it be that people are open enough to try insects? Do they really care if it is in a bar or not? They're just going to try it anyway because they're adventurous enough and open enough to try" 
(Participant 2). Insect products have primarily been delivered without the visual resembling of the insect ingredients used. Interviewees also have negative opinions about the visualisation which affects customers' acceptance of the product. "So as long as you can make something that they [the consumers] are very familiar with, you can start to introduce new ingredients" (Participant 10). Secondly, it is difficult to get insect products approved as human food products. There is substantial information required from business organisation, which SMEs are not capable of providing. In addition, there is a risk that they may disclose private information and their possible competitive advantages to competitors. Insect producers are also unwilling to submit joint applications. "One of the issues that isn't surprising is about sharing commercially confidential information with other companies, especially when you are a start-up, with particular ideas about insect farming or processing, you don't want to give your game away to competitors” (Participant 4).

\section{Restrictive Regulations}

Regulatory frameworks on the use of edible insects for human food chains are perceived to be extremely strict for new products in the market. Interviewees have revealed their disappointment at the oppressive restrictions imposed. Certain insects with a recorded history of global consumption are now required to go through an extensive food product application process. Applications for the use of insects in the human food chain are more extensive in the EU than in other countries. "For those [non-EU] applications, there is a slipstream, but you don't have to fill out a form. It's an arduous process” (Participant 3). Another approval method discussed by the interviewees is the comprehensive scientific approval process. This kind of approval needs extensive and sustained research into the safety of the insect species as food. "Another approach is a full scientific approval approach, which needs proof of food safety over time, and a massive dossier of proof and 
documents" (Participant 1). Costs to fund the application are substantial. It was emphasised that "the cost and time put into applications is believed to be in excess of what organisations can fund” (Participant 10).

A high degree of uncertainty about the development of regulations has also been emphasised by the interviewees. "We've had periods where we thought we might have to stop selling everything or even the business" (Participant 3). The continued regulatory uncertainty is also recognised as the primary reason for the absence of sustained investment. Large-scale capital investment in the edible insect sector is currently viewed as deficient. "Because the big factors are uncertain, people aren't keen to lend you money" (Participant 9). An area of particular ambiguity identified by our interviewees was whether insects approved through Novel Food Applications would be available to any business. "If one company wanted to sell battered crickets or domestic crickets, another company might be able to do exactly the same and piggyback on that approval, and there is a lot of uncertainty about that” (Participant 2).

\section{Discussion and implication}

\section{Optimising the insect production procedure and practices to reduce costs}

Insect production/rearing practices were considered underdeveloped by many of the interviewees. The interviewees emphasised the lack of consensus about the optimal conditions for rearing edible insects as human food on a commercial scale. Insect feeding material composition and rearing practices have a significant impact on the performance metrics of the farming process and the quality and quantity of the outputs. Insects grow at different rates in relation to their habitual diet. In addition, rearing processes, such as feeding, collection, cleaning and rehousing, highly depend on manual labour (Dobermann 
et al., 2017), which lead to high labour costs (Rumpold and Schlüter, 2013). As 75\% of rearing costs are sourced from labour in the edible insect sector (Lynley, 2018), it is essential to integrate automation into production and processing stages in order to reduce the dependence on labour and its associated costs. Automation has been successfully implemented into a substantial range of processes within animal agriculture, e.g. dairy farming represents the most automated agricultural production system, with almost all processes automated (Edan et al., 2009). A selection of insect farming and processing facilities situated outside of the UK, e.g. the Netherlands, have been recognised to have also progressed further along in their application of processing technologies.

Intensive energy demands were also considered a challenge to achieving competitive pricing levels. Regardless of insect species, temperature is a key factor that heavily influences the growth of insects (Bjørge et al., 2018). Some species even demand extra heat throughout the year in the UK. As temperature increases, so does insect growth and production output - the temperature selection should aim to achieve a predetermined acceptable level of productivity whilst minimising overall energy costs, as adequate insulation of rearing facilitates has a significant impact on the energy costs of heating. Effectively utilising waste heat from other processes is another strategy used to reduce energy costs, so locating insect farms to nearby facilities producing large quantities of wasted thermal energy may be useful.

Selection of feeding materials also has a significant impact on overall production costs, constituting $60-70 \%$ of the annual cost of traditional animal agriculture (Becker, 2008). Reducing the pricing through utilisation of alternative feed sources is a priority for edible insects. A variety of waste products can no longer be legally used as feed for animals in 
human food chains (Stamer, 2015). Excessive prices and the difficulties of sourcing have been stressed by our interviewees, which is in line with Shelomi’s study (2015). Utilising materials that would otherwise be disposed e.g. food waste from food production would benefit the edible insect sector, and developing links with local food businesses for plantbased waste was stated as an advantage by our interviewees. Sourcing waste from these local businesses may not only provide a more competitive price but also improve local food waste management. Using food waste in a similar fashion has been observed in other agriculture sectors (Hill, 2019). However, sourcing feed from food businesses should be undertaken with caution, to ensure compliance with legal frameworks. Currently, catering wastes, obtained from premises such as home kitchens, restaurants, canteens and cafes, cannot be legally used as feed for farm animals (DEFRA, 2019).

Another key strategy for reducing costs is through the selective breeding of insects for their specific productivity related factors. Insects, as a result of their poikilothermic bodies (their internal temperature can change), have a higher feed conversion efficiency (Oonincx et al., 2015). However, as stated by the interviewees, the insects used were not bred for rearing. Selective breeding has yielded significant results in productivity in other animal agriculture industries. For example, within the broiler chicken industry, where extensive selective breeding is employed, the growth of broiler chickens has exponentially grown between 1957 and 2005 by an additional 400\%, as well as a decrease in the feed conversion ratio of 50\% (Zuidhof et al., 2014). This extensive selective breeding has been accompanied with a series of health consequences for the animals (Zuidhof et al., 2014), therefore a more restrained approach to edible insects is preferable. Productivity is not the sole aim of selective breeding - a beneficial nutrient profile is another important consideration when producing insects for human consumption (Mason et al., 2018). 


\section{Encouraging business collaboration}

Lack of collaboration between the businesses in the edible insect sector is another barrier to upscaling production. Due to the novelty of the sector, companies avoid opportunities for joint application, or joint farming/processing to prevent giving potential competitors a perceived competitive advantage obtained through innovative practices or established conditions. Therefore, it is very difficult for organisations in the edible insect sector to pool resources together due to their concerns about the confidentiality of their production and processing procedures. One strategy to alleviate this issue is developing co-operative relationships on a horizontal level across the edible insect sector in order to identify opportunities to create new values together (Zineldin, 2004). An alternative strategy would be the creation of an independent organisation, for example, the Woven Network in the UK, to protect private sector data, and manage applications for multiple applicants.

\section{Providing training and education to insect farmers}

Shortage of production expertise and knowledge on human food requirements means there is a significant risk of losing control of the outcome of their productions (Cohen, 2018). There are a substantial variety of factors influencing the outcome of the insect rearing process, such as temperature, light, humidity, ventilation, rearing containers, population density, feed and water availability, feed composition and quality (Dobermann et al., 2017), and the increased availability of education/training about rearing, processing and selling insects for human consumption would be beneficial for the edible insect sector. In addition, people in the sector lack commercial experience. Industry representatives/ network development could be beneficial for the sector development too. For example, the National Farmers Union can host workshops or provide the literature to farmers. 


\section{Reducing uncertainty about regulatory frameworks}

Uncertainty about regulatory frameworks started in the beginning of 2018 (Dobermann et al., 2017). The application process for the authorisation of an insect species as human food has two distinct paths, the 'standard procedure' and the 'notification procedure' (IPIFF, 2018b). In the notification procedure, insect species traditionally consumed within the diets of non-EU nations have access to a streamlined application process, consisting of the notification of a certain food as "traditional” from a third country (IPIFF, 2018b). However, this approval procedure, although the simplified version, is it still considered resourceintensive for industry organisations. As part of the application the organisation must provide a dossier of evidence that the insect species has been consumed on a continual basis for at least 25 years as a traditional food product (IPIFF, 2018b). The standard procedure requires impractically high investment levels for the organisations within this developing industry, as an extensive dossier of scientific data is required for the standard procedure including aspects such as a full analysis of the strategy for safety evaluation (IPIFF, 2018b).

Although industry representatives were primarily worried about the framework, they were also unsure about new procedures. EU Regulation 2015/2283 stated that all novel food authorisations, by default, applied to all foods in the approved category (IPIFF, 2019) and that there was a 'data protection provision’ (Cook, 2018). This allows organisations to submit an application to request a five-year data protection period and to exclusively sell an insect species for that five-year period (Cook, 2018). This is demonstrated in the temporary patent system used by the pharmaceutical industry (Marchini, 2013), which allows innovative organisations to benefit from the "first mover advantage" and to establish 
themselves strongly in the market. However, there are also concerns about multinational organisations who will enter the market, and cause a negative impact on competition as a result of the data protection provision (Cook, 2018). Investment and innovation will continue to suffer from an absence of properly established and upheld legislation (Fabrizio, 2013 and de-Magistris et al., 2015).

\section{Conclusion, limitations and future research}

This study represents an initial attempt to shed light on the upscaling of the production capacity of the edible insect sector in the UK. The edible insect sector faces a number of significant challenges in upscaling their production capacity and growth in its early status of product development. This study has identified five primary challenges for upscaling production capacity, including insect feeding materials, production processes, expertise and knowledge, new product development and regulatory uncertainty. Based on the current situation (high production costs and regulatory uncertainty), this study has made several recommendations for businesses. Firstly, investment in labor-saving technology e.g. automation, is needed to reduce labour expenditure if the industry is to benefit from economies of scale. Secondly, development in the "optimal method" for commercial rearing (e.g. the rearing process, temperature and insect feeding materials) are essential to improving food quality and safety and, in the meantime, to reducing production costs. With the dominance of pricing as a key factor influencing food choice within the UK (Jones et al., 2014), one of the priorities for the edible insect sector is to moderate costs by upscaling production capacity and adopting process technologies. Therefore, the first challenge in designing effective policy is to clearly guideline production process, which includes optimising insect production procedures and practices, the sources of insect feeding material and breed selection. In addition, across the industry, policy makers also need to 
encourage business collaboration, provide training/education to insect farmers and reduce regulatory uncertainty in order to implement specific production policies and achieve the upscaling of production and long-term growth.

However, there are a few drawbacks to this study: as this study was based on interviews considering specific situations in the UK, the results may not benefit other countries, which have different backgrounds and situations. In future research, quantitative studies can be conducted to find out more comprehensively the extent that each barrier affects upscaling production capacity. Future research can also focus on collaboration and co-operation between members in the sector and help policy makers to develop regulatory frameworks to support sector development. In addition, further research into culture and consumer acceptance is also critical to establish an empirical base to make product development decisions.

\section{References}

Alexy, U., Janz, N. and Kersting, M. (2017) “31 - Food and Meals in Vegetarian Children and Adolescents”, in Mariotti, F. (ed.) Vegetarian and Plant-Based Diets in Health and Disease Prevention. Academic Press, 549-564.

Becker, G.S. (2008) “Livestock Feed Costs: Concerns and Options”, CSR report for Congress.

Berners-Lee, M., Hoolohan, C., Cammack, H. and Hewitt, C.N. (2012) “The relative greenhouse gas impacts of realistic dietary choices”, Energy Policy, 43, 184-190.

Bjørge, J.D., Overgaard, J., Malte, H., Gianotten, N. and Heckmann, L.H. (2018) “Role of temperature on growth and metabolic rate in the tenebrionid beetles Alphitobius diaperinus and Tenebrio molitor”, Journal of Insect Physiology, 107, 89-96. 
Boddy C. R. (2016) “Sample size for qualitative research”, Qualitative Market Research: An International Journal, 19(4), 426-432.

Braun, V. and Clarke, V. (2006) “Using thematic analysis in psychology”, Qualitative Research in Psychology, 3(2), 77-101.

Brunner, T.A. and Nuttavuthisit, K. (2019), "A consumer-oriented segmentation study on edible insects in Switzerland and Thailand", British Food Journal, Vol. 122 No. 2, pp. $482-488$

Caparros Megido, R., Gierts, C., Blecker, C., Brostaux, Y., Haubruge, É., Alabi, T. and Francis, F. (2016) “Consumer acceptance of insect-based alternative meat products in Western countries”, Food Quality and Preference, 52, 237-243.

Celia, G., Andrew, J., Jonathan, H., Toni, H. and Gemma, C. (2016) “The Greenhouse Gas Emissions of Various Dietary Practices and Intervention Possibilities to Reduce This Impact”, in Impact of Meat Consumption on Health and Environmental Sustainability. Hershey, PA, USA: IGI Global, 1-26.

Codex Alimentarius Commission (2010) “Agenda item 13: comments of Lao PDR: proposal for the new work and development of regional standard for edible crickets and their products (CRD 8)”, 17th Session of the FAO/WHO Coordinating Committee for Asia (CCASIA).

Cohen, A.C. (2018) “Ecology of Insect Rearing Systems: A Mini-Review of Insect Rearing Papers from 1906-2017”, Advances in Entomology, 6(2), 30.

Cook, J. (2018) Potential Impact of New EU Novel Food Legislation. Available at: https://www.sgs.com/en/news/2018/04/potential-impact-of-new-eu-novel-food-legislation (Accessed: 23/08/2019).

Cortes Ortiz, J.A., Torres Ruiz, A., Morales-Ramos, J., Thomas, M., Rojas, M.G., Tomberlin, J., Yi, L., Han, R., Giroud, L. and Jullien, R.L. (2016) “Insect Mass 
Production Technologies”, in Insects as Sustainable Food Ingredients Production, Processing and Food Applications, edited by Dossey, A. T. 53-201.

de-Magistris, T., Pascucci, S. and Mitsopoulos, D. (2015), "Paying to see a bug on my food: How regulations and information can hamper radical innovations in the European Union", British Food Journal, 117(6), 1777-1792.

DEFRA (2019) Supplying and using animal by-products as farm animal feed.

Denyer, D. and Tranfield, D. (2009) "Producing a systematic review”, in Buchanan, D.A. and Bryman, A. (Eds.): The SAGE Handbook of Organizational Research Methods, SAGE Publications Ltd., London, England, 671-689.

Dobermann, D., Swift, J.A. and Field, L.M. (2017) “Opportunities and hurdles of edible insects for food and feed”, Nutrition Bulletin, 42(4), 293-308.

Edan, Y., Han, S. and Kondo, N. (2009) “Automation in Agriculture”, in Nof, S.Y. (ed.) Springer Handbook of Automation. Berlin, Heidelberg: Springer Berlin Heidelberg, 1095-1128.

Fabrizio, K.R. (2013) “The Effect of Regulatory Uncertainty on Investment: Evidence from Renewable Energy Generation”, The Journal of Law, Economics and Organization, 29 (4), 765-798.

Food Ingredients First (2018) New novel food rules will "pave the way" for wider insect use. Available at: https://www.foodingredientsfirst.com/news/new-novel-food-rules-willpave-the-way-for-wider- insect-use.html (Accessed: 08/08/2019).

Halloran, A., Roos, N., Eilenberg, J., Cerutti, A. and Bruun, S. (2016) “Life cycle assessment of edible insects for food protein: a review”, Agronomy for Sustainable Development, 36(4), 57. 
Han, R., Shin, J.T., Kim, J., Choi, Y.S. and Kim, Y.W. (2017) “An overview of the South Korean edible insect food industry: challenges and future pricing/promotion strategies”, Entomological Research, 47(3), 141-151.

Hartmann, C., Shi, J., Giusto, A. and Siegrist, M. (2015) “The psychology of eating insects: A cross- cultural comparison between Germany and China”, Food Quality and Preference, 44, 148-156.

Hill, C. (2019) A bug's life - How industrious insects are recycling food waste for farmers.

Hoffman, R. (2017) "Micronutrient deficiencies in the elderly - could ready meals be part of the solution?”, Journal of Nutritional Science, 6, e2.

Hoffmann, V.H., Trautmann, T. and Hamprecht, J. (2009) “Regulatory Uncertainty: A Reason to Postpone Investments? Not Necessarily”, Journal of Management Studies, 46(7), 1227-1253.

IPIFF (2018a) The European insect sector today: Challenges, opportunities and regulatory landscape. IPIFF: IPIFF IPIFF.

IPIFF (2018b) Regulation (EU) 2015/2283 on novel foods

IPIFF (2019) Regulation (EU)2015/2283 on novel foods. 23/08/2019: IPIFF IPIFF. Jones, N.R.V., Conklin, A.I., Suhrcke, M. and Monsivais, P. (2014) “The growing price gap between more and less healthy foods: analysis of a novel longitudinal UK dataset”, PloS one, 9(10), e109343-e109343.

Kouřimská, L. and Adámková, A. (2016) “Nutritional and sensory quality of edible insects”, NFS Journal, 4, 22-26.

Lähteenmäki-Uutela, A., Hénault-Ethier, L., Marimuthu, S.B., Talibov, S., Allen, R.N., Nemane, V., Vandenberg, G. and Józefiak, D. (2018) “The impact of the insect 
regulatory system on the insect marketing system”, Journal of Insects as Food and Feed, 4, 1-12.

Lynley, M. (2018) Ovipost wants to help drop the labor cost of building cricket farms. Marchini, K.A. (2013) "Patents and innovation in the pharmaceutical industry”, Grove City CJL Pub Pol'y, 4, 47.

MacEvilly, C. (2000) “Bugs in the system”, Nutrition Bulletin, 25, 267-268.

Oonincx, D.G.A.B., van Broekhoven, S., van Huis, A. and van Loon, J.J.A. (2015) "Feed Conversion, Survival and Development, and Composition of Four Insect Species on Diets Composed of Food By-Products”, PloS one, 10(12), e0144601-e0144601.

Parkes, A. (2018) Meat-free Foods - UK - September 2018. Mintel: Mintel Mintel.

[Online]. Available at: http://academic.mintel.com/display/859399/ (Accessed: 14/06/2019).

Payne, C.L.R., Dobermann, D., Forkes, A., House, J., Josephs, J., McBride, A., Müller, A., Quilliam, R.S. and Soares, S. (2016) "Insects as food and feed: European perspectives on recent research and future priorities”, Journal of Insects as Food and Feed, 2(4), 269276.

Payne, C.L.R., Scarborough, P., Rayner, M. and Nonaka, K. (2015) “Are edible insects more or less “healthy' than commonly consumed meats? A comparison using two nutrient profiling models developed to combat over- and undernutrition”, European Journal of Clinical Nutrition, 70, 285.

Poortvliet, P.M., Van der Pas, L., Mulder, B.C. and Fogliano, V. (2019) “Healthy, but Disgusting: An Investigation into Consumers” Willingness to Try Insect Meat”, Journal of Economic Entomology, 112(3), 1005-1010.

Qu, S. (2011) “The qualitative research interview”, Qualitative Research in Accounting \& Management, 8(3), 238-264. 
Raheem, D., Carrascosa, C., Oluwole, O.B., Nieuwland, M., Saraiva, A., Millán, R. and Raposo, A. (2019) “Traditional consumption of and rearing edible insects in Africa, Asia and Europe”, Critical Reviews in Food Science and Nutrition, 59(14), 2169-2188. Rumpold, B.A. and Schlüter, O.K. (2013) "Potential and challenges of insects as an innovative source for food and feed production”, Innovative Food Science \& Emerging Technologies, 17, 1-11.

Saunders, M., Lewis, P. and Thornhill, A. (2008) Research methods for business students. Pearson Education M.U.A.

Scarborough, P., Appleby, P.N., Mizdrak, A., Briggs, A.D.M., Travis, R.C., Bradbury, K.E. and Key, T.J. (2014) "Dietary greenhouse gas emissions of meat-eaters, fish-eaters, vegetarians and vegans in the UK”, Climatic Change, 125(2), 179-192.

Schabel, H.G. (2010) “Forest insects as food: A global review”, Forest insects as food: Humans bite back, 37-64.

Shelomi, M. (2015) “Why we still don't eat insects: Assessing entomophagy promotion through a diffusion of innovations framework”, Trends in Food Science \& Technology, 45(2), 311-318.

Stamer, A. (2015) “Insect proteins—a new source for animal feed”, EMBO reports, 16(6), 676-680.

Taylor, G. and Wang, N. (2018) "Entomophagy and allergies: a study of the prevalence of entomophagy and related allergies in a population living in North-Eastern Thailand”, Bioscience Horizons: The International Journal of Student Research, 11.

Tuomisto, H.L. and Teixeira de Mattos, M.J. (2011) “Environmental Impacts of Cultured Meat Production”, Environmental Science \& Technology, 45(14), 6117-6123. 
van der Weele, C., Feindt, P., Jan van der Goot, A., van Mierlo, B. and van Boekel, M. (2019) “Meat alternatives: an integrative comparison”, Trends in Food Science \& Technology, 88, 505-512.

Winther, A. (2018) Attitudes towards Sports Nutrition - UK - June 2018 (Accessed: 12/08/2019).

Wolk, A. (2017) 'Potential health hazards of eating red meat', Journal of Internal Medicine, 281(2), 106-122.

Yin, R. K. (2017). Case study research and applications: Design and methods. Thousand Oaks, CA: Sage.

Zineldin, M. (2004) “Co-opetition: the organisation of the future”, Marketing Intelligence \&amp; Planning, 22(7), 780-790.

Zuidhof, M.J., Schneider, B.L., Carney, V.L., Korver, D.R. and Robinson, F.E. (2014) “Growth, efficiency, and yield of commercial broilers from 1957, 1978, and 20051”, Poultry Science, 93(12), 2970-2982. 